\title{
DESAFIOS DE PROFESSORES DO SEXO MASCULINO NA EDUCAÇÃO INFANTIL: UM OLHAR SOBRE AS PESQUISAS
}

\author{
CHALLENGES MEN'S TEACHERS IN CHILDHOOD EDUCATION: A LOOK AT RESEARCH \\ DESAFIOOS DE LOS HOMBRES MAESTROS EN NIÑEZ EDUCACIÓN: UNA MIRADA PARA \\ LAS BÚSQUEDAS
}

\author{
Glauber César Cruz Custódio \\ Jairo Antônio da Paixão
}

\begin{abstract}
RESUMO
Pode se perceber, nos últimos anos, o aumento gradativo da presença de professores do sexo masculino na educação infantil, etapa esta que constitui a primeira fase da educação básica brasileira. Dessa forma, este estudo buscou apresentar e analisar as produções acadêmicas a respeito da docência de professores homens na educação infantil. Trata-se de um trabalho de revisão sistemática do tipo estado da arte, em três bancos de dados: Banco de Dissertações e Teses da CAPES; Trabalhos das reuniões da ANPEd; periódicos específicos em Educação com Qualis A1. Abarcou-se pesquisas desenvolvidos entre $2010 \mathrm{e}$ 2018. Pode se perceber a escassez de trabalhos na temática da docência masculina na educação infantil. Os resultados mostram que os professores homens da educação infantil enfrentam diversos desafios, como o olhar de desconfianças pelos colegas da escola e da sociedade, olhar de estranhamento na escola, vigilância exacerbada limitações impostas no trabalho, entre outros desafios. Diante desse cenário, pode se dizer que tais apontamentos são muito importantes para que se tenha a conscientização de que não existe espaço preestabelecido para homem ou mulher e que ambos são capazes.
\end{abstract}

PALAVRAS-CHAVE: Professores homens. Educação Infantil. Docência.

\begin{abstract}
In the last few years, there has been a gradual increase in the presence of male teachers in early childhood education, a stage that constitutes the first phase of basic education in Brazil. Thus, this study sought to present and analyze academic productions regarding the teaching of male teachers in early childhood education. This is a state-of-the-art systematic review work in three databases: CAPES Dissertations and Theses Bank; Work of ANPEd meetings; Specific journals in Education with Qualis A1. Research carried out between 2010 and 2018 was covered. It is possible to notice the scarcity of works on the theme of male teaching in early childhood education. The results show that male teachers of early childhood education face several challenges, such as the look of suspicion by colleagues at school and society, the look of strangeness at school, exacerbated surveillance, limitations imposed at work, among other challenges. In view of this scenario, it can be said that such notes are very important in order to be aware that there is no pre-established space for men or women and that both are capable.
\end{abstract}

KEYWORDS: Male teachers. Child education. Teaching.

\section{RESUMEN}

En los últimos años, se ha producido un aumento gradual de la presencia de profesores varones en la educación infantil, etapa que constituye la primera fase de la educación básica en Brasil. Así, este estudio buscó presentar y analizar producciones académicas en torno a la docencia de profesores varones en educación infantil. Este es un trabajo de revisión sistemática de última generación en tres bases de datos: CAPES Dissertations y Theses Bank; Trabajo de reuniones ANPEd; Revistas específicas en Educación con Qualis A1. Se cubrió la investigación realizada entre 2010 y 2018. Se puede notar la escasez de trabajos sobre el tema de la enseñanza masculina en la educación infantil. Los resultados muestran que los profesores varones de educación infantil se enfrentan a varios desafíos, como la mirada de sospecha

Revista de Ciências Humanas, Frederico Westphalen - RS, v. 21, n.2, p. 25-42, maio/ago. 2020.

Recebido em: 03/03/2020 $\quad$ Aceito em: 25/04/2020


de los colegas en la escuela y la sociedad, la mirada de extrañeza en la escuela, las limitaciones de vigilancia exacerbadas impuestas en el trabajo, entre otros desafíos. Ante este escenario, se puede decir que tales notas son muy importantes para ser conscientes de que no existe un espacio preestablecido para hombres o mujeres y que ambos son capaces.

PALABRAS CLAVE: Profesores varones. Educación Infantil. Enseñanza.

\title{
CONSIDERAÇÕES INICIAIS
}

\begin{abstract}
Para entender o momento atual, em qualquer circunstância, é necessário compreender que não somos vividos, constituídos apenas do hoje, mas que somos reflexo de tantos outros sujeitos, tempos, experiências e acontecimentos (MORENO, 2017, p. 61)
\end{abstract}

Atualmente, no Brasil, a Educação Infantil é compreendida como a primeira etapa da Educação Básica, mas, nem sempre foi assim, até a década de 1980, era uma etapa anterior, independente e preparatória para as fases posteriores da escolarização básica, que só começava no ensino fundamental, situando, dessa forma fora da Educação Formal (BRASIL, 2017).

De acordo com Pereira (2012), a educação infantil, em seu início tinha perspectiva completamente direcionada à assistência social, demorando um significativo tempo para se desvincular desta "alcunha assistencialista". Souza (2018) revela que os rumos da educação infantil começaram a mudar com a promulgação da Constituição Federal de 1988, influenciada pelo movimento pró creche pela Declaração Universal dos Direitos Humanos. Ademais, Ramos (2011, p.10) descreve que

essa Constituição rompeu com a figura do amparo e da assistência presentes nas Constituições anteriores e determinou em seu art. 208 que é dever do Estado 0 atendimento em creches e pré-escolas às crianças de zero a seis anos de idade. Em seguida, a Lei de Diretrizes e Bases da Educação Nacional (LDBEN/9394/1996) inseriu a educação infantil como primeira etapa da educação básica, tornando gratuito esse atendimento.

É importante destacar que, a tramitação da LDBEN perdurou por oito anos, devido a diversas disputas de diferentes setores da sociedade, e, finalizado esse processo, com promulgação da mesma em 1996, a educação infantil, finalmente, ao menos no campo legal, deixou a esfera da assistência social para situar-se na educação (SOUZA, 2018).

Nessa ambiência, Sousa (2011, p. 19) menciona que "a profissão docente nessa etapa passou a ter uma configuração diferente daquela em que qualquer pessoa podia exercer a função docente com crianças bastando apenas que gostasse de crianças, não carecendo de formação". A LDBEN determinou, em seu artigo 62, que

a formação de docentes para atuar na educação básica far-se-á em nível superior, em curso de licenciatura, de graduação plena, em universidades e institutos superiores de educação, admitida, como formação mínima para o exercício do magistério na educação infantil e nas quatro primeiras séries do ensino fundamental, a oferecida em nível médio, na modalidade Normal. (BRASIL, 1996, p. 20) 
Não obstante, cabe aqui relatar que a educação infantil tem como finalidade 0 desenvolvimento integral da criança de até 5 (cinco) anos, em seus aspectos físico, psicológico, intelectual e social, complementando a ação da família e da comunidade (BRASIL, 2013). Destacase que a educação infantil passou a atender a faixa etária de 0 a 5 anos após a modificação introduzida na LDB no ano de 2006, que antecipou o ingresso ao Ensino Fundamental para os 6 anos de idade (BRASIL, 2017). Uma especificidade da educação infantil é que a prática docente nessa fase se dá através de ações indissociáveis entre o educar e o cuidar das crianças, ou seja, a educação e o cuidado como aspectos interdependentes que se entrecruzam no trabalho com as crianças (SOUSA, 2011).

Assim, é importante mencionar que na docência na educação infantil sempre se teve a hegemonia da presença feminina, em que esse predomínio tem raízes históricas antigas, ocorrendo ao longo da história, quer antes ou depois da institucionalização da educação nesse nível de escolarização (SOUSA, 2011). Moreno (2017) aponta que a docência na educação, ou especificadamente, na educação infantil é muito associada à figura feminina, em virtude do percurso histórico, social e cultural por trás da profissão.

Uma sinopse estatística da Educação Básica desenvolvida pelo Instituto Nacional de Pesquisas Educacionais Anísio Teixeira (INEP), no ano de 2018, mostra que os homens professores constituem minoria, sendo que dos mais de dois milhões de professores no Brasil, aproximadamente $80 \%$ destes eram mulheres. Monteiro e Altmann $(2014$, p. 722 ) revelam que "quanto menor a idade da criança atendida, menor a participação masculina na docência", ou seja, por ser a primeira etapa da educação básica, a educação infantil tem ainda menos professores homens do que as outras etapas da educação básica.

Nessa realidade, de acordo com Souza (2010), se faz presente "padrões estereotipados de gênero e de papéis associados ao masculino e ao feminino, geralmente fundamentados em argumentos biológicos que naturalizam características que são, na verdade, construídas histórica e culturalmente" (p.115). Por sua vez, Sousa (2011, p.34) menciona que

Isto não seria uma especificidade da educação infantil, porém, é uma característica histórica que não pode ser negada. É fato irrefutável na história e na atualidade que as mulheres são maioria extrema em se tratando da docência na educação infantil.

Todavia, apesar de se perceber um crescimento da presença masculina na docência na Educação Infantil conforme os últimos levantamentos realizados pelo INEP, em suas sinopses estatísticas da educação básica, realizadas anualmente, os professores homens na educação infantil ainda são minoria (BRASIL, 2018). Ao citar Cardoso (2007), Sousa (2011, p. 24) relata que "chama atenção para o fato de que, por existirem poucos homens na docência com crianças pequenas, há uma tendência a ficarem na invisibilidade, chegando ao ponto de se pensar que não existem".

Haja vista o cenário apresentado, é ainda mais significativo pesquisar sobre professores homens na educação infantil uma vez que poderá auxiliar para que se possa tornar visível a minoria masculina na profissão (SOUSA, 2011). Concorda-se com Santos (2015), ao descrever que é errado pensar que os professores homens, por representarem um pequeno percentual não

Revista de Ciências Humanas, Frederico Westphalen - RS, v. 21, n.2, p. 25-42, maio/ago. 2020. 
possam ser considerados, tendo em vista que independente do percentual atingido, este grupo merece ser pesquisado, observado e debatido. Além disso, concorda-se com, Silva (2015, p. 17) ao descrever que

\begin{abstract}
Ignorar as repercussões da inserção de tais profissionais na educação infantil também é, do mesmo modo, ignorar alunos, familiares, colegas, gestores e a sociedade em geral que vem interagindo com esses homens professores. Tais interações, mesmo que ainda incipientes, são existentes no cenário educacional brasileiro e local, e precisam ser problematizadas para que se vislumbre a possibilidade de desnaturalização de estereótipos de gênero associados a homens e mulheres no cotidiano da educação infantil.
\end{abstract}

Neste âmbito, destaca-se que após o levantamento realizado foi possível perceber que a temática da docência de professores homens na educação infantil ainda é pouco pesquisada no Brasil, constituindo como uma temática relevante na ambiência da educação infantil e à docência nesse contexto. Dessa maneira, buscando compreender o que as pesquisas atuais dizem a respeito da temática, esta investigação objetivou apresentar e analisar as produções acadêmicas a respeito da docência de professores homens na educação infantil.

É importante mencionar que, com este estudo, parte-se do pressuposto descrito por Thin (2006), ao descrever que, quando se elabora uma forma de abordar e examinar uma questão, a faz geralmente com o propósito de ultrapassar os discursos, pontos de vistas ou questões que aparentam ser insuficientes.

O texto deste trabalho está organizado de maneira que, primeiramente, tem-se a parte introdutória do estudo seguida da metodologia e de um levantamento sobre o que as pesquisas realçam sobre a temática em questão. Posteriormente, tem-se uma seção que discorre sobre os desafios dos professores homens atuantes na educação infantil. Por fim, são descritas as considerações finais do trabalho.

\title{
METODOLOGIA
}

Esta investigação se caracteriza como uma pesquisa de natureza qualitativa na qual, segundo Minayo (2011), trabalha-se com um universo de significados, motivos, aspirações, crenças, valores e atitudes. Isso se refere a um espaço mais profundo das relações, dos processos e dos fenômenos, que não podem ser reduzidos à operacionalização de variáveis.

Trata-se de um trabalho de revisão sistemática, que, de acordo com Atallah e Castro (1998) visa possibilitar a integração das informações de um conjunto de investigações científicas realizadas separadamente sobre determinado fenômeno ou realidade, constituindo- se um método de avaliação de um conjunto de dados de maneira simultânea.

Em conformidade com Teixeira e Caminha (2013), citando Mulrow (1994) uma revisão sistemática visa propiciar a interpretação e identificação das categorias representativas de uma realidade particular, ou também servindo para identificar temas que revelam a necessidade de comprovações, funcionando assim como uma orientação para pesquisas futuras.

Este trabalho de revisão é pode ser definido como o que se conceituam como estado da arte, que, em conformidade com Haddad (2000), possibilita, em um recorte temporal estabelecido, desenvolver a sistematização de trabalhos de uma área de conhecimento, realizando a

Revista de Ciências Humanas, Frederico Westphalen - RS, v. 21, n.2, p. 25-42, maio/ago. 2020.

Recebido em: 03/03/2020

Aceito em: 25/04/2020 
identificação dos principais resultados, as temáticas e a abordagem dos estudos, permitindo encontrar lacunas e temáticas que não foram exploradas e que compõem campo relevante para 0 desenvolvimento de estudos.

O levantamento se constituiu na busca de trabalhos publicados em três diferentes bancos de dados: Banco de dados da Dissertações e Teses da Coordenação de Aperfeiçoamento de Pessoal de Nível Superior (CAPES); Trabalhos apresentados nas reuniões da Associação Nacional de Pós-Graduação e Pesquisa em Educação (ANPEd); periódicos específicos em Educação com classificação Qualis A1.

No levantamento (estado da arte) foram abarcados, trabalhos publicados na atual década, ou seja, do ano de 2010 a 2018. Para a busca dos estudos foram utilizados os seguintes descritores: professores homens na educação Infantil; professores do sexo masculino na educação infantil; educação infantil e professores homens.

No que se refere ao mapeamento realizado no banco de dados das reuniões anuais da ANPEd, primeiramente é importante salientar que este ocorreu em dois grupos de trabalho (GT), especificadamente no GT 07- Educação de Crianças de 0 a 6 anos e no GT 23 - Gênero, sexualidade e Educação. Para a escolha desses grupos de trabalho levou-se em consideração seus históricos e temáticas abordadas e sua relação com a temática da pesquisa aqui proposta.

Para seleção dos trabalhos se analisava os seus títulos, palavras-chaves e resumos. Dessa forma, os estudos considerados potenciais, foram selecionados e lidos de maneira mais aprofundada para verificar se estes se enquadravam na temática da pesquisa ora proposta. Ressalta-se que para o trabalho ser selecionado, ele deveria evidenciar em seu título ou resumo que discorria sobre a temática desta pesquisa.

Após a realização do levantamento e a seleção dos trabalhos, de acordo com o critério de seleção, foi realizada a leitura e fichamento dos trabalhos, para, posteriormente, ser iniciada a produção do texto. Os trabalhos encontrados dentro da temática e do recorte do estudo, subdivididos por banco de dados, são apresentados nos quadros nos apêndices deste artigo.

\section{CONHECENDO AS PESQUISAS SOBRE A TEMÁTICA}

Buscando compreender o que as pesquisas dizem sobre professores homens na educação infantil foi realizado um mapeamento de trabalhos que se enquadravam na temática abordada, chegando-se, assim, a um total de 22 trabalhos: No banco de teses e dissertações da Capes foram encontradas 17 dissertações de mestrado, 2 teses de doutorado. No banco de dados das Reuniões da ANPEd foram encontrados 2 artigos. Dentre os dez periódicos Qualis A1 em educação foi encontrado somente 1 artigo científico na temática aqui proposta.

No mapeamento de trabalho no banco de teses e dissertações da Capes, foram encontrados os seguintes estudos: As dissertações de Souza (2010), Sousa (2011), Ramos (2011), Pereira (2012), Alves (2012), Nunes (2013), Monteiro (2014), Gomides (2014), Silva (2014), Silva (2015), Teodoro (2015), Hentges (2015), Mendonça (2016), Moreno (2017), Ferreira (2017), Faria (2018) e Souza (2018). As teses de Santos (2015) e Lima (2017). Os artigos de Monteiro e Altmann (2013) e Souza (2015) das reuniões da ANPEd e o artigo publicado em

Revista de Ciências Humanas, Frederico Westphalen - RS, v. 21, n.2, p. 25-42, maio/ago. 2020. 
periódico de Monteiro e Altmann (2014). Trabalhos estes que será trago alguns apontamentos a seguir:

No ano de 2010 foi publicado o trabalho de Souza (2010) pela Universidade de São Paulo, teve 0 intuito de investigar de que maneira um homem se constitui professor de creche, nas relações com suas colegas, com a direção e com as crianças e suas famílias. Para isso, utilizou como instrumentos de coleta de dados a observação e a entrevista. A autora realça que a direção escolar afasta esses professores homens de atividades com as meninas buscando tranquilizar as famílias. Na escola a presença do professor homem é fortemente associada a imagem do pai. Diante disso considera-se que a inserção desse professor na educação infantil percorre de um estranhamento inicial à uma relação de maior confiança posteriormente.

No ano seguinte foram publicadas duas dissertações. Pela Universidade Federal do Ceará, Sousa (2011) teve como objetivo investigar como se dá o ingresso e a trajetória de homens professores em duas instituições de educação infantil. 0 estudo teve uma abordagem qualitativa, e, para tal, realizou análise documental, observações e entrevistas. Em seus resultados, destacase a condição de que se tem uma representação da prática docente na educação infantil como um espaço feminino, colocando a mulher como maias adequada para ocupar a docência nesse contexto em virtude de terem mais jeito com as crianças. Contudo, a autora indica que para as crianças tanto faz o gênero do professor

Nesse mesmo ano, a pesquisa de mestrado desenvolvida por Ramos (2011), na Pontifícia Universidade Católica de Minas Gerais (PUC-MG), buscou investigar o ingresso e a permanência de professores homens na educação de crianças pequenas em instituições públicas de educação infantil. Para tanto, a partir de uma pesquisa qualitativa, utilizando a entrevista e grupos de discussão como instrumento de dados. Evidenciou-se que os professores homens da educação infantil são encaminhados para outras funções, como professor de apoio ou de crianças maiores, que requerem menos cuidados. Além disso têm que provar ter as habilidades e competências para o trabalho na educação infantil.

Objetivando compreender como ocorre a construção da identidade do professor homem na educação infantil, nesse ambiente com hegemonia de mulheres, sob a perspectiva de gênero, no exercício da profissão docente em creches e pré-escolas, Pereira (2012), realizou sua investigação pela Universidade Federal de São Paulo. Para esse fim utilizou a perspectiva das histórias de vida de professores para a coleta dos dados. Dentre seus resultados, constatou-se que a escola reproduz preconceitos da sociedade, determinando que os professores homens mantenham distanciamento dos corpos das crianças. A autora destaca que estranho não é ter homens como professores da educação infantil, estranho é ter somente mulheres.

Alves (2012), desenvolveu uma investigação pela Universidade de Fortaleza, que objetivou compreender a experiência vivida pelos professores homens atuantes na educação infantil, na rede pública municipal de Fortaleza. Trata-se de uma pesquisa qualitativa com abordagem fenomenológica utilizando as entrevistas para a coleta das informações. A autora revela que se tem uma ideia estereotipada de que o ser mulher é único para docência de maneira adequada e ensino de crianças por terem características ausentes no homem. Dessa forma, o estudo revelou caminhos para se quebrar essas diferenças, descontruindo esses mitos e preconceitos que os distanciam e ainda insistem em se fazer presente.

Revista de Ciências Humanas, Frederico Westphalen - RS, v. 21, n.2, p. 25-42, maio/ago. 2020. 
Por sua vez, Nunes (2013), pela Pontifícia Universidade Católica de Goiás, desenvolveu sua pesquisa que teve como objetivo investigar e analisar o professor homem na educação infantil da rede municipal de ensino de Rio Verde (GO) e como este é percebido pela comunidade escolar. A partir de uma pesquisa qualitativa, adotou-se os seguintes instrumentos para coleta de dados: estudo bibliográfico, análise documental, aplicação de questionários e entrevistas. Por desconfiarem da possibilidade de acontecer algo, familiares e colegas de trabalho relatam que algumas atividades deveriam ser realizadas somente pelas mulheres, excluindo os professores homens dessa possibilidade. Percebeu-se, diante dos resultados da investigação que é estabelecido diferenças de gênero no ambiente escolar da educação infantil.

Com o objetivo de analisar as trajetórias de professores homens na educação infantil da rede municipal de ensino de Campinas/ SP, Monteiro (2014) executou seu estudo pela Universidade Estadual de Campinas. Em uma perspectiva qualitativa, através de um viés antropológico das histórias de vida, adotando as entrevistas para a coleta dos dados. Em um espaço de predominância das mulheres, percebeu-se questionamentos quanto a presença de professor homem na educação infantil e quanto a sua orientação sexual. Dessa maneira, se fez presente tentativas de segregação desses professores homens, os conduzindo a turmas com alunos mais velhos, mudanças de aluno, ou, até mesmo abaixo assinado para retirada do professor.

Outra investigação foi realizada no mesmo ano, agora na Universidade Federal de Viçosa, por Gomides (2014). Esta pesquisa sobre a imersão de homens na educação infantil, objetivou compreender o percurso de homens e mulheres nessa fronteira de indefinições identitárias, buscando visualizar as suas trajetórias de singularização construídas. A partir de uma pesquisa qualitativa que utilizou como instrumento para coleta de dados as entrevistas. $O$ autor revela em seu estudo que a percepção da sociedade de que a mulher é mais "apta" para a função, perpassa várias esferas além da educacional. Percebeu-se que, diante do cenário imposto, os professores homens não se sentem pertencentes a este ambiente. Contudo, estes professores não tentam alterar essa condição, evitando encontros e se protegendo em cargos administrativos.

Silva (2014), em sua pesquisa desenvolvida pela Universidade Estadual de Campinas, identificar como ocorrem as relações de poder nos espaços e tempos das pré-escolas públicas, quando há homens na docência. Adotou-se de uma pesquisa qualitativa com inserção etnográfica, utilizando-se da observação de perto com os professores e as crianças pequenas. A pesquisa revela em seus resultados que a presença do professor homem na educação infantil leva a um temor das famílias, relatando que a mídia influencia no comportamento dessas pessoas, principalmente no que se refere a casos de pedofilia. De acordo com o autor essa situação sinaliza discriminações e propaga desigualdades de gênero da profissão docente. Dessa maneira, o autor reforça que as diferenças entre os sexos estão presentes, porém não podem ser transformadas em desigualdades, ao invés disso, deve-se criar formas de extinção das hierarquias de gênero.

No ano seguinte foram publicados quatro trabalhos, o primeiro deles, desenvolvido por Santos (2015) na Pontifícia Universidade Católica de São Paulo teve como objetivo ter um olhar sobre as histórias de vida de professores homens da primeira infância, buscando compreender 0 significado de ser e estar na educação e cuidado de crianças pequenas. Adotou-se de uma investigação qualitativa, por meio da observação do trabalho desses professores. 0 estudo 
mostrou que a presença do professor homem na educação infantil gera diversas situações de conflito e de estranhamento, ao mesmo tempo que desperta dúvidas quanto à sexualidade desses docentes. Contudo, a autora indica que o enfrentamento dessas dificuldades pode contribuir para uma discussão mais ampla que possa auxiliar no rompimento de estereótipos, preconceitos e discriminações.

O segundo trabalho, foi desenvolvido por Silva (2015), pela Universidade Federal do Rio Grande do Norte, e objetivou analisar as implicações da presença de professores homens na Educação Infantil, problematizando as relações de gênero a partir de um mescla de aspectos sociais, históricos e culturais. Para tal, utilizou entrevistas semiestruturadas para coletas dos dados, a partir de estudo qualitativo. $O$ estudo revela que as questões de gênero se mostram como significativos obstáculos a serem vencidos pelos professores homens na educação infantil, em virtude de implicar mudanças socioculturais. $O$ autor reforça que seu estudo tem como perspectiva a desnaturalização de estereótipos de gênero na educação infantil, funcionando como um exercício de resistência cultural e histórica.

O terceiro estudo, realizado por Teodoro (2015) pelo Centro Universitário Moura Lacerda, teve como objetivo analisar as percepções de professores homens que da educação infantil sobre a atuação profissional desempenhada em relação à especificidade da educação infantil e, também, a percepção da comunidade sobre a atuação dos mesmos nesse cenário. Utilizou-se de uma pesquisa qualitativa, tendo como instrumento para recolha dos dados as entrevistas semiestruturadas. Nos resultados de sua investigação, o autor revela que a sociedade enxerga apenas a figura feminina como apta para trabalho com as crianças. Relata que as famílias das crianças reagem com estranhamento e/ ou resistência quanto a presença de um professor homem na educação infantil. Dessa forma 0 autor ressalta que a quebra desse paradigma feminino na educação infantil possibilitará que a criança tenha tanto professores homens quanto mulheres, e que ambos podem zelar por elas.

O quarto trabalho, desenvolvido na Universidade Federal de Pelotas, com autoria de Hentges (2015), almejou conhecer as representações das direções de escolas de Educação Infantil sobre homens professores/ auxiliares, de maneira a identificar o que pensam as diretoras sobre as masculinidades presentes no espaço escolar, bem como, compreender se é oportunizada ou dificultada a inserção dos homens nesse cenário. Por meio de um estudo de natureza qualitativa, utilizando a entrevista semiestruturada para a coleta dos dados. Os resultados da pesquisa revelam que os homens dificilmente realizam atividades que demandem contato corporal com as crianças, sendo os professores homens visto com desconfiança pelas famílias, além da suspeita acerca da sexualidade dos professores homens. Dessa forma, o estudo mostrou que se tem uma divisão de tarefas entre os sexos nesse cenário, possibilitando perceber, também, que as questões de gênero, sexualidade e masculinidade atravessam as interações entre os diversos atores do ambiente escolar, sejam eles pais, crianças e as professoras e professores.

No ano subsequente, foi encontrado um trabalho, desenvolvido por Mendonça (2016) na Pontifícia Universidade Católica de São Paulo. Este estudo teve como objetivo investigar as condições que percorrem à docência e o trabalho gestor de profissionais homens no Centro de Educação Infantil. $O$ estudo foi realizado através de uma perspectiva qualitativa, do tipo analíticadescritiva, tendo como instrumentos para a coleta de dados a análise documental e as entrevistas 
semiestruturadas individuais. Os resultados evidenciaram que a presença do professor homem em um espaço majoritariamente feminino é possível sim, contudo faz-se necessário as discussões e reflexões, que possam promover a ruptura de discursos e práticas sexistas e dos papéis específicos de gênero.

Posteriormente, Lima (2017), pela Universidade Federal de Pernambuco, teve como objetivo o estudo da construção identitária profissional docente de homens atuantes na educação infantil e séries iniciais, a partir de suas trajetórias. A partir de uma pesquisa qualitativa adotou-se a entrevista narrativa como instrumento para a coleta dos dados. Os resultados da pesquisa realçam que os constrangimentos experienciados pelos professores homens ocasionam mal-estar que implica fronteiras nas ações exercidas entre homens e mulheres em sala de aula. A autora indica que a prática docente requer muito mais do que os atributos da maternagem.

Moreno (2017) em sua investigação realizada na Pontifícia Universidade Católica do Rio de Janeiro, almejou conhecer e compreender como as trajetórias de vida fizeram com que os homens escolhessem o ofício da docência na Educação Infantil, além disso, buscou-se analisar o processo de inserção e permanência dos professores e perceber como a memória e as experiências contribuíram para o desenvolvimento da identidade profissional desses docentes. Adotou-se uma abordagem qualitativa na investigação, tendo as entrevistas como instrumento para coleta dos dados. Os resultados de sua pesquisa revelam que por se tratar de um território compreendido como espaço feminino, percebeu-se que a inserção de professores homens, foi experenciada como com estranhamento pelos diferentes agentes das comunidades escolares. Apesar de estarem em um espaço feminino não têm a tendência de se feminizarem, possibilitando, assim, quebrar com a tradição de que educar e cuidar são próprios dos seres humanos e não de um gênero ou sexo.

Outra pesquisa, executada por Ferreira (2017) na Universidade Federal de Minas Gerais, objetivou investigar as relações de cuidado de professores homens nos equipamentos públicos de Educação Infantil da Prefeitura de Belo Horizonte. Este estudo se caracteriza como uma pesquisa qualitativa, utilizando como instrumento para a recolha dos dados questionário e entrevistas realizadas com diversos atores da instituição escolar. 0 estudo revelou que os professores homens que atuam em ações de cuidado passam por momentos de vigilância. Diante disso, as maiores dificuldades dos professores homens nesse contexto se referiram à situação da higienização das crianças e a desconfiança da comunidade escolar.

Faria (2018), pela Universidade Federal da Grande Dourados, desenvolveu sua pesquisa que teve como objetivo elucidar a participação masculina na história da docência com crianças. Por meio de uma pesquisa qualitativa, e utilizando como instrumento para a recolha dos dados a entrevista. 0 estudo revela que a vigilância dos pais e familiares, conduzia os professores a necessidade de que comprovassem sua confiança e competência para a continuação do trabalho docente com crianças. Dessa maneira, o estudo aponta que quando se reduz a responsabilidade da educação de crianças à aspectos construídos socialmente, desconsidera a importância da capacitação profissional de modo a preparar o docente no exercício da profissão, independentemente de gênero ou sexo.

Buscando-se compreender as táticas e estratégias de permanência utilizadas por homens atuantes na docência da Educação Infantil, Souza (2018) desenvolveu seu estudo pela 
Universidade Estadual de Minas Gerais. A autora adotou uma abordagem qualitativa em sua pesquisa, tendo como instrumento para a recolha dos dados a entrevista narrativa. Os resultados revelam que a maior dificuldade relatada pelos professores foi a situação do estranhamento que os colegas de trabalho tinham sobre eles. Sendo que suas colegas de trabalho compreendiam que o espaço escolar da educação infantil não deveria ser dividido com homens, pois, apesar de terem a mesma formação acadêmica, acreditava que os homens não tinham os atributos necessários para exercerem a docência nesse cenário. Diante dessas situações os professores homens adotam diversas estratégias para conseguirem permanecer atuando, como, por exemplo, 0 professor homem se impor enquanto profissional. Dessa maneira, a autora considera que as estratégias/ táticas para permanência como docentes da educação infantil se fez importante para desconstruir certezas e levantar reflexões.

Já no que se refere ao banco de dados das Reuniões da ANPEd, destaca-se que dentre os 182 trabalhos publicados nos dois grupos de trabalho abarcados nesse estudo, entre os anos de 2010 e 2018, foi encontrado somente 2 estudos na temática aqui proposta, estes que, neste momento, serão apresentados.

O primeiro deles, produzido por Monteiro e Altmann (2013) e publicado no GT 23 Gênero, Sexualidade e Educação, da $36^{a}$ Reunião da ANPEd, teve como objetivo analisar 0 período inicial da trajetória profissional de homens que optaram por atuar como professores de educação infantil. Por meio de uma pesquisa qualitativa que empregou como instrumentos para a recolha dos dados as entrevistas, inspiradas nas histórias de vida, a partir de uma perspectiva de gênero. Os resultados de seus estudos revelam que no ingresso e a permanência de professores homens na educação infantil se faz presente diferentes dificuldades referentes ao contexto de atuação, e por meio de questionamentos e segregação desses professores homens na educação infantil, cenário este de hegemonia feminina. Com a pesquisa, as autoras reforçam que abordar a presença/ausência de professores homens atuando nesse contexto permite desnaturalizar a ideia de que a docência na educação infantil ser uma profissão do gênero feminino.

O segundo trabalho, com autoria de Souza (2015) foi publicado no GT 07 - Educação de Crianças de 0 a 6 anos, da $37^{\text {a }}$ Reunião da ANPEd, e objetivou discutir a respeito da visão de crianças de uma turma de um Centro de Educação Infantil sobre o ingresso e a trajetória de um professor homem na instituição escolar. 0 estudo se caracteriza como uma pesquisa qualitativa, adotando como instrumento para a coleta dos dados a observação e entrevistas semiestruturadas com os diferentes atores da comunidade escolar. 0 estudo indicou que que os professores homens que escolhem atuar na educação infantil, dificilmente seguem carreira duradoura. Indica que mesmo que passem determinado tempo nesse encargo, abrindo uma possibilidade encontram algum mecanismo para que abandonem a atuação docente com as crianças.

Já no que se refere ao levantamento realizado nos dez periódicos Qualis A1 em educação, é importante destacar que dentre os 4706 artigos publicados nestes entre os anos de 2010 e 2018 , foram encontrados somente 1 artigo que se enquadrava na temática deste trabalho. Esta pesquisa foi desenvolvida por Monteiro e Altmann (2014) e publicada na revista Cadernos de Pesquisa. Discorrendo a respeito da presença de homens na educação infantil, o estudo teve como objetivo analisar o período inicial da trajetória de professores homens que optaram por atuar na educação infantil. A partir de uma pesquisa qualitativa, utilizaram a entrevista, na perspectiva das histórias 
de vida, como instrumento para a coleta dos dados. O estudo revelou que o professor homem da educação infantil sofre diferentes questionamentos por ter escolhido desenvolver sua carreira em um cenário considerado pela comunidade escolar como feminino. $O$ estudo destacou que a análise das trajetórias desses professores homens na educação infantil possibilitou mostrar que a educação infantil é um cenário de atuação para ambos, sejam homens ou mulheres.

Ao se imaginar e relacionar o grande quantitativo de estudos produzidos em programas de pós-graduação, das pesquisas publicadas nos periódicos selecionados neste trabalho, e, ainda, o quantitativo de trabalhos das reuniões da ANPED, com o número de trabalhos produzidos/ encontrados na temática de professores homens na educação infantil nesses bancos de dados, evidencia a escassez de trabalho produzidos na temática.

No que concerne a localização geográfica das dissertações e teses desenvolvidas na temática, pode se perceber que grande parte dos trabalhos, ou seja 12 estudos (63\%) foram produzidos na Região Sudeste. Esse dado vai ao encontro do quadro quantitativo de produções de teses e dissertações da Capes, que indica que a maior produção de trabalhos se dá na região Sudeste. Os demais trabalhos foram produzidos nas seguintes regiões e quantidade: Região Nordeste com 4 trabalhos; Região Centro-Oeste com 2 trabalhos e a Região Sul com 1 trabalho.

Já no que se refere a metodologia abordada nas dissertações, teses, artigos das reuniões da ANPED e artigos dos periódicos abarcados neste trabalho, percebeu se que todas as investigações foram de natureza qualitativa. No que tange aos instrumentos utilizados para as investigações tiveram-se o estudo bibliográfico, análise documental, questionário, entrevistas (semiestruturadas e narrativas) grupos de discussão e observação. Dentre os instrumentos utilizados tem-se a predominância da utilização das entrevistas.

Analisando os trabalhos selecionados, pode-se perceber que eles sinalizam diversos desafios enfrentados pelos professores homens na educação infantil, desafios estes que vão limitar as possibilidades desses professores. Dentre os desafios revelados pelos estudos com professores homens atuantes na educação infantil, destacam-se os relacionados ao olhar de desconfiança da sociedade; a desconfiança das famílias dos alunos; a desconfiança dos colegas de trabalho; o olhar de estranhamento da comunidade escolar ao professor homem; a vigilância exacerbada aos docentes do sexo masculino; as limitações impostas ao trabalho dos professores homens na educação infantil;

Além destes, têm se, também os desafios relacionados as distinções de gênero; 0 desafio da concepção de que a mulher é mais apta que o homem para a docência na educação infantil; desafio da desconfiança da capacidade profissional do professor homem, tendo este que provar diariamente suas capacidades para se manter na profissão; desafio dos professores homens terem permanência duradoura na atividade docente de crianças; Desafio da imposição para a mudança de área de atuação, por exemplo, mudança para áreas de gestão ou áreas administrativas, ou até mesmo influências para estes abandonarem a carreira; entre outros desafios. Desafios estes que agora serão trazidos alguns apontamentos das investigações abarcadas nesse trabalho.

PROFESSORES HOMENS NA EDUCAÇÃO INFANTIL: DESAFIOS DA DOCÊNCIA NESSE CENÁRIO 
A literatura mostra que os professores homens da educação infantil estão imersos em um cenário em que vão conviver com variados desafios, inseridos em um local marcado pela diferenças e desconfortos, que abre possibilidades de discussão e reflexão de variadas temáticas, como pode se citar as questões de gênero, preconceitos, valores, entre outros, que diversas vezes não são esclarecidas de maneira clara, e que, por conseguinte, não contribuem para transformações (PEREIRA, 2012).

Um primeiro aspecto que cumpre ser relatado diz respeito a desconfiança da sociedade sob a atuação de professores homens na educação infantil. Segundo Ferreira (2017), a sociedade vê como inconcebível um homem num espaço definido historicamente como feminino como é o caso da Educação Infantil. Souza (2018) revela que os professores são vistos, a partir do senso comum, com desconfiança, seja pelas famílias ou colegas de trabalho. Nessas circunstâncias, Moreno (2017, p.75) revela que os professores homens da educação infantil enfrentam "a desconfiança da índole, dúvidas da postura e sexualidade, além do "pé-atrás" no fazer pedagógico".

Nunes (2013) descreve que a presença de homens atuando como professores na educação infantil é motivo de estranhamento, não somente das mulheres professoras das escolas, como também das famílias e de toda sociedade. Esse estranhamento ocasiona, de acordo com Ramos (2011), uma vigilância permanente, na qual os profissionais da instituição escolar observam com muita atenção as ações e atitudes desses professores homens. Ferreira (2017) revela que a vigilância é necessária para a proteção dos envolvidos, contudo, descreve que esta deve ser realizada em mesma medida tanto para homens quanto para mulheres.

Os professores homens da educação infantil se deparam com um outro desafio, 0 questionamento quanto à sua orientação sexual (MONTEIRO; ALTMANN, 2014). As autoras revelam que se tem um permanente questionamento a respeito da orientação sexual e da masculinidade dos professores homens da educação infantil. Nessa ambiência, Ramos (2011, p.127) revela que

os professores do sexo masculino, ao ingressarem na educação infantil, têm sua sexualidade colocada em suspeição: de um lado, apresenta se a dúvida, se escolheram uma profissão feminina é porque não são homens de verdade. Por outro lado, destaca a "crença disseminada de um homem sexuado, ativo, perverso e que deve ficar distante do corpo das crianças.

É exigido na escola que os professores homens da educação infantil mantenham certo distanciamento dos corpos dos alunos (PEREIRA, 2012). De acordo com Hentges (2015), os docentes homens não se envolvem em atividades que demandem o afeto e contato físico, como, por exemplo, abraço, o colo, ou contato corporal muito próximo. Assim, a autora argumenta que

Com isso fica evidente que, além de uma divisão por cargos dentro das escolas, há ainda uma divisão de tarefas e atividades pelo sexo dos funcionários, 0 que muitas vezes faz com que os profissionais fiquem limitados às atividades de seu cargo e às atribuídas a seu sexo (p.58)

Nessa situação se faz presente um aspecto de gênero, que de acordo com Scott (1992) representa um modo de referir à organização social das relações entre os sexos, encontrando se uma construção social e cultural que busca indicar como devemos ser e agir nos variados contextos. Além disso, o gênero indica um modo de se referir à organização social das relações entre os sexos e um termo para teorizar a questão das diferenças sexuais, compreendido como uma construção cultural e social (MAIA; MAIA, 2005).

Revista de Ciências Humanas, Frederico Westphalen - RS, v. 21, n.2, p. 25-42, maio/ago. 2020. 
Princípios que foram construídos cultural e socialmente relacionam à mulher como mais apta para educar, com seus princípios de sensibilidade e cuidado (MENDONÇA, 2016). Em conformidade com a referida autora, assemelham-se à prática educativa com as atividades domésticas e do lar realizada pelas mulheres, tendo uma enraizada ideia de que cuidar seja essencialmente uma função feminina. Por sua vez, Teodoro (2015, p. 53) realça que "para o senso comum, o homem não tem as qualidades requeridas para o exercício cotidiano do saber-fazer pedagógico para realizar o trabalho com as crianças". Cumpre aqui salientar, também, que a compreensão de que a mulher é mais apta para a docência na educação infantil perpassa além da esfera educacional (GOMIDES, 2014).

Diante dessa circunstância, o professor homem da educação infantil tem que provar diariamente sua capacidade, passando por uma espécie de "período comprobatório (RAMOS, 2011). De acordo com o autor nesse período o professor tem que provar possuir as habilidades necessárias para a educação de crianças pequenas, cuidando das mesmas com competência. Nessa perspectiva, Teodoro (2015) indica que o professor homem da educação infantil "precisa assumir posturas comprobatórias para estar e continuar na carreira e, pelo elencado acima, 0 domínio da especificidade profissional que a faixa etária da criança exige para a sua atuação [...]".

Dessa forma, emerge um outro desafio, o desafio de permanência na profissão. Santos (2015) realça que os professores homens têm que ter fortes convicções para permanecerem na profissão, em virtude das frequentes confrontações, pressões sociais e não aceitação dos mesmos na educação de crianças. Estes professores sofrem influencias para abandonarem à docência com crianças pequenas e seguirem para cargos burocráticos, administrativos, ou trabalhe com alunos mais velhos, ou até mesmo buscarem outra profissão de modo a não terem ligação direta com a sala de aula (TEODORO, 2015). Essa situação ocasiona, segundo Monteiro e Altmann (2014), pressões visando a "extinção" da presença do professor homem na educação infantil através de abertura de abaixo assinado solicitando formalmente a retirada desse professor da sala de aula ou da escola.

\section{CONSIDERAÇÕES FINAIS}

Em face aos diferentes aspectos apresentados neste trabalho a respeito da presença do professor homem na educação infantil, cumpre aqui descrever que, concordando-se com Ferreira (2017), é possível mencionar que a imersão de professores homens como professores da Educação Infantil constitui um significativo passo em direção da conscientização de que há espaço preestabelecido na sociedade para o homem ou a mulher, e que as ações dos professores na educação infantil pode ser desempenhada por ambos profissionais, sem distinção em ser homem ou mulher.

Ser professor homem ou mulher na Educação Infantil não deve ser o que importa, aspectos importantes e significativos são a ética enquanto profissional, a formação acadêmica, competência, habilidades técnicas e profissionais do indivíduo, entre outros, seja este sujeito do sexo masculino ou feminino. Diante disso, cumpre aqui trazer o descrito por Santos (2015), ao descrever que se espera que a presença de professores homens na educação infantil descontrua estereótipos, tendo em vista que a presença masculina nesse cenário provoca o novo, provoca

Revista de Ciências Humanas, Frederico Westphalen - RS, v. 21, n.2, p. 25-42, maio/ago. 2020.

Recebido em: 03/03/2020

Aceito em: 25/04/2020 
reflexões, provoca a revisão de concepções e mudanças sobre os papéis dos homens e das mulheres na sociedade.

Dessa maneira, é necessário realizar discussões, reflexões e promover a integração de produções acadêmicos-cientificas na esfera da prática docente de professores homens na educação infantil de maneira a minimizar os desafios desses professores nesse cenário. Para tal, faz-se necessário a conscientização, de modo a quebrar os paradigmas equivocados que se fazem presente, para que, assim, seja possivel alcançar mecanismos efetivos de enfrentamento e minimização dessa problemática.

\section{REFERÊNCIAS}

ALVES, B. F. A experiência vivida de professores do sexo masculino na educação infantil: uma questão de gênero? Mestrado em psicologia Instituição de Ensino: Universidade De Fortaleza, Fortaleza Biblioteca Depositária: Universidade de Fortaleza, 2012.

ATALLAH, A. N.; CASTRO, A. A..Revisão sistemática da literatura e metanálise. Medicina baseada em evidências: fundamentos da pesquisa clínica. São Paulo: Lemos-Editorial, p. 42-8, 1998.

BRASIL. INEP, Estatísticas.2018 Disponível em: http://inep.gov.br/web/guest/sinopsesestatisticas-da-educacao-basica. Acesso em: 24 mai. 2019.

BRASIL. Lei n. 12.796, de 4 de abril de 2013. Altera a Lei n 9.394, de 20 de dezembro de 1996, que estabelece as diretrizes e bases da educação nacional, para dispor sobre a formação dos profissionais da educação e dar outras providências. Diário Oficial da União, 2013.

BRASIL. Lei n. 9.394 de 20 de novembro de 1996. Estabelece as diretrizes e bases da educação nacional. Diário Oficial da União, Brasília, DF, 23 dez. 1996, Seção 1, p. 2783327841.

BRASIL. Ministério da Educação. Secretaria da Educação Básica. Base Nacional Comum Curricular. Terceira versão. Brasilia: MEC 2017. Disponível em:<http://portal.mec.gov.br/index.php?option=com_docman\&view=download\&alias=79601anexo-texto-bncc-reexportado-pdf-2\&category_slug=dezembro-2017-pdf\&ltemid=30192 > Acesso em: 28 mai. 2019.

FARIA, A H. Trajetórias docentes: memórias de professores homens que atuaram com crianças no interior de Mato Grosso do Sul (1962-2007). 2018. 112 f. Dissertação (Mestrado em Educação) Universidade Federal Da Grande Dourados, Dourados.

FERREIRA, W. N. As relações de cuidado e de gênero presentes nos relatos de homens professores nas Unidades Municipais de Educação Infantil de Belo Horizonte. 2017. $160 \mathrm{f}$. Dissertação (Mestrado Profissional em Educação e Docência) Universidade Federal de Minas Gerais, Belo Horizonte. 
GOMIDES, W. L. T. Transitando na fronteira: a inserção de homens na docência da educação infantil. 2014. 79 f. Dissertação (Mestrado em Educação) Universidade Federal De Viçosa, Viçosa.

HADDAD, S. O Estado da arte das pesquisas em educação de jovens e adultos no Brasil (A produção discente da pós-graduação em educação no período 1986-1998). Ação Educativa, São Paulo, 2000.

HENTGES, K. J. Homens na educação infantil: o que pensam as diretoras sobre isso?. 2015. 90 f. (Mestrado em Educação) Universidade Federal De Pelotas, Capão do Leão.

LIMA, M. C. S. Tornar-se professor: um estudo sobre a formação de identidades profissionais de professores do sexo masculinodos anos iniciais, a partir de suas trajetórias. 2017. 220 f. Tese (Doutorado em Educação) Universidade Federal De Pernambuco, Recife.

MAIA, A. C. B.; MAIA, A. F. Sexualidade e Infância. Bauru: FC/CECEMCA: Brasília: MEC/SEF, 204f.,Cadernos Cecemca, n.1, 2005.

MENDONÇA, M. M. Impacto da presença de gestores e professores homens em centros de educação infantil: alguns elementos para compreensão. 2016. 129 f. Dissertação (Mestrado em Educação) Pontifícia Universidade Católica De São Paulo, São Paulo.

MINAYO, M. C. S. (Org.) Pesquisa Social: teoria, método e criatividade. 30. ed. Petrópolis: Vozes, 2011.

MONTEIRO, M. K.; ALTMAN, H. Trajetórias na docência: professores homens na educação infantil. In: 36a Reunião Nacional da ANPED, 2013, Goiânia/GO. Anais.... Disponível em: http://36reuniao.anped.org.br/pdfs_trabalhos_aprovados/gt23_trabalhos_pdfs/gt23_2689_texto.p df. Acesso em: 24 Mai. 2019.

MONTEIRO, M. K. Trajetórias na docência: professores homens na educação infantil. 2014. 152 f. Dissrtação (Mestrado em Educação Física) Universidade Estadual De Campinas, Campinas.

MONTEIRO, M. K.; ALTMANN, H. Homens na educação infantil: olhares de suspeita e tentativas de segregação. Cadernos de pesquisa, v. 44, n. 153, p. 720-741, 2014.

MORENO, R. R. M. Professores Homens na Educação Infantil do Município do Rio de Janeiro: Vozes, Experiências, Memórias e Histórias. 2017. 154 f. Dissertação (Mestrado em Educação) Pontifícia Universidade Católica do Rio De Janeiro, Rio de Janeiro.

NUNES, P. G. Docência e gênero: um estudo sobre o professor homem na educação infantil da rede municipal de ensino de Rio Verde (GO). 2013. 126 f. Dissertação (Mestrado em Educação) Pontifícia Universidade Católica de Goiás, Goiânia.

PEREIRA, M. A. B. Professor-homem na Educação Infantil: a construção de uma identidade. 2012. 160 f. Dissertação (Mestrado em Educação) Universidade Federal de São Paulo, São Paulo. 
RAMOS, J. Um estudo sobre os professores homens da educação infantil e as relações de gênero na rede municipal de Belo Horizonte - M.G. 2011. 139 f. Dissertação (Mestrado em Educação) Pontifícia Universidade Católica de Minas Gerais, Belo Horizonte.

SANTOS, E. S. A presença masculina na creche: estariam os educadores homens fora de lugar?. 2015. 160 f. Tese (Doutorado em Educação) Pontifícia Universidade Católica de São Paulo, São Paulo.

SCOTT, J. História das Mulheres. In:BURKE, P.(Org.).A escrita da História: novas perspectivas. São Paulo: Editora da Universidade Estadual Paulista, 1992.

SILVA, B. L. B. A presença de homens docentes na educação infantil: lugares (des)ocupados. 2015. 107 f. Dissertação (Mestrado Em Educação) Universidade Federal do Rio Grande Do Norte, Natal.

SILVA, P. R. Não sou pai, nem tio, sou professor! A docência masculina na educação infantil. 2014180 f. Dissertação (Mestrado em Educação). Universidade Estadual de Campinas, Campinas.

SOUSA, J. E. Por acaso existem homens professores de educação infantil?:dois estudos de caso em representações sociais. 2011. 208 f. Dissertação (Mestrado em Educação) Universidade Federal do Ceará, Fortaleza.

SOUZA, E. B. Quebrando tabus e educando a infância: a permanência de homens nas unidades municipais de educação infantil de Belo Horizonte. 2018. 104 f. Dissertação (Mestrado em Educação) Universidade do Estado de Minas Gerais, Belo Horizonte.

SOUZA, J. E. Homem docência com crianças pequenas: um olhar das crianças de um centro de educação infantil. In: Reunião Nacional da ANPED, 37, Floriánopolis, 2015.

Anais...Floriánopolis, 2015.

SOUZA, M. I. Homem como professor de creche: sentidos e significados atribuídos pelos diferentes atores institucionais. 2010. 248p. Dissertação (Mestrado) - Faculdade de Filosofia, Ciências e Letras de Ribeirão Preto, Universidade de São Paulo, Ribeirão Preto, 2010.

TEIXEIRA, F. L. S.; CAMINHA, I. O. Preconceito no futebol feminino brasileiro: uma revisão sistemática. Movimento, v. 19, n. 1, p. 265, 2013.

TEODORO, L. G. 0 trabalho docente na educação infantil na perspectiva de professores homens de um município do interior paulista. 2015. 122 f. Dissertação (Mestrado em Educação) Centro Universitário Moura Lacerda, Ribeirão Preto.

THIN, D. Para uma análise das relações entre famílias ara uma análise das relações entre famílias populares e escola: confrontação entre lógicas socializadoras. Revista Brasileira de Educação. Rio de Janeiro, v.11. n.32, p. 211-225, 2006. 


\section{APÊNDICE A}

Quadro 1 -Dissertações e teses na temática de professores homens na educação infantil do banco de dados da Capes.

\begin{tabular}{|c|c|c|c|c|}
\hline Titulo & Autor & Ano & $\begin{array}{l}\text { Dissertação/tes } \\
\mathrm{e}\end{array}$ & Instituição \\
\hline $\begin{array}{l}\text { Homem como professor de creche: sentidos e } \\
\text { significados atribuídos pelos diferentes atores } \\
\text { institucionais. }\end{array}$ & $\begin{array}{l}\text { Maria Isis de } \\
\text { Souza }\end{array}$ & 2010 & Dissertação & USP \\
\hline $\begin{array}{l}\text { "Por acaso existem homens professores de } \\
\text { educação infantil?": um estudo de casos múltiplos } \\
\text { em representações sociais }\end{array}$ & $\begin{array}{l}\text { José Edilmar de } \\
\text { Sousa }\end{array}$ & 2011 & Dissertação & UFC \\
\hline $\begin{array}{l}\text { Um estudo sobre os professores homens da } \\
\text { educação infantil e as relações de gênero na rede } \\
\text { municipal de Belo Horizonte - M.G }\end{array}$ & Joaquim Ramos & 2011 & Dissertação & PUC-MG \\
\hline $\begin{array}{l}\text { Professor homem na educação infantil: a } \\
\text { construção de uma identidade }\end{array}$ & $\begin{array}{c}\text { Maria Arlete } \\
\text { Bastos Pereira }\end{array}$ & 2012 & Dissertação & UNIFESP \\
\hline $\begin{array}{l}\text { A experiência vivida de professores do sexo } \\
\text { masculino na educação infantil: uma questão de } \\
\text { gênero? }\end{array}$ & $\begin{array}{c}\text { Benedita } \\
\text { Francisca Alves }\end{array}$ & 2012 & Dissertação & UNIFOR \\
\hline $\begin{array}{l}\text { Docência e gênero: um estudo sobre o professor } \\
\text { homem na educação infantil da rede municipal de } \\
\text { ensino de Rio Verde (GO) }\end{array}$ & $\begin{array}{l}\text { Patrícia Gouvêa } \\
\text { Nunes }\end{array}$ & 2013 & Dissertação & PUC - GO \\
\hline $\begin{array}{l}\text { Trajetórias na docência: professores homens na } \\
\text { educação infantil }\end{array}$ & $\begin{array}{l}\text { Mariana Kubilius } \\
\text { Monteiro }\end{array}$ & 2014 & Dissertação & UNICAMP \\
\hline $\begin{array}{l}\text { Transitando na fronteira: a inserção de homens na } \\
\text { docência da educação infantil }\end{array}$ & $\begin{array}{l}\text { Wagner Luiz } \\
\text { Tavares } \\
\text { Gomides }\end{array}$ & 2014 & Dissertação & UFV \\
\hline $\begin{array}{l}\text { Não sou tio, nem pai, sou professor!: a docência } \\
\text { masculina na Educação Infantil }\end{array}$ & $\begin{array}{l}\text { Peterson Rigato } \\
\text { da Silva }\end{array}$ & 2014 & Dissertação & UNICAMP \\
\hline $\begin{array}{l}\text { A presença masculina na creche: estariam os } \\
\text { educadores homens fora de lugar? }\end{array}$ & $\begin{array}{l}\text { Elsa Santana } \\
\text { dos Santos }\end{array}$ & 2015 & Tese & PUC - SP \\
\hline $\begin{array}{l}\text { A presença de homens docentes na educação } \\
\text { infantil: lugares (des)ocupados }\end{array}$ & $\begin{array}{l}\text { Bruno Leonardo } \\
\text { Bezerra da Silva }\end{array}$ & 2015 & Dissertação & UFRN \\
\hline $\begin{array}{l}\text { O trabalho docente na educação infantil na } \\
\text { perspectiva de professores homens de um } \\
\text { município do interior paulista }\end{array}$ & $\begin{array}{l}\text { Luciano } \\
\text { Gonçalves } \\
\text { Teodoro }\end{array}$ & 2015 & Dissertação & CUML \\
\hline $\begin{array}{l}\text { Homens na Educação Infantil: o que pensam as } \\
\text { diretoras sobre isso? }\end{array}$ & $\begin{array}{l}\text { Karine Jacques } \\
\text { Hentges }\end{array}$ & 2015 & Dissertação & UFPel \\
\hline
\end{tabular}




\begin{tabular}{|l|c|c|c|c|}
\hline $\begin{array}{l}\text { Impacto da presença de gestores e professores } \\
\text { homens na eduç̧ão infantil: alguns elementos } \\
\text { para compreensão }\end{array}$ & $\begin{array}{c}\text { Michele Mariano } \\
\text { Mendonça }\end{array}$ & 2016 & Dissertação & PUC - SP \\
\hline $\begin{array}{l}\text { Tornar-se professor: um estudo sobre a formação } \\
\text { das identidades profissionais de professores do } \\
\text { sexo masculino dos anos iniciais, a partir de suas } \\
\text { trajetórias }\end{array}$ & $\begin{array}{c}\text { Maria da } \\
\text { Conceição Silva } \\
\text { Lima }\end{array}$ & 2017 & Tese & UFPE \\
\hline $\begin{array}{l}\text { Professores Homens na Educação Infantil do } \\
\text { Município do Rio de Janeiro: Vozes, Experiências, } \\
\text { Memórias e Histórias }\end{array}$ & $\begin{array}{l}\text { Rodrigo Ruan } \\
\text { Merat Moreno }\end{array}$ & 2017 & Dissertação & PUC-RJ \\
\hline $\begin{array}{l}\text { As relações de cuidado e de gênero presentes nos } \\
\text { relatos de homens professores nas Unidades } \\
\text { Municipais de Educação Infantil de Belo Horizonte }\end{array}$ & $\begin{array}{l}\text { Waldinei do } \\
\text { Nascimento } \\
\text { Ferreira }\end{array}$ & 2017 & Dissertação & UFMG \\
\hline $\begin{array}{l}\text { Trajetórias docentes: memórias de professores } \\
\text { homens que atuaram com crianças no interior de } \\
\text { Mato Grosso do Sul (1962-2007) }\end{array}$ & $\begin{array}{c}\text { Adriana Horta } \\
\text { de Faria }\end{array}$ & 2018 & Dissertação & UFGD \\
\hline $\begin{array}{l}\text { Quebrando tabus e educando a infância: a } \\
\text { permanência de homens nas Unidades Municipais } \\
\text { de Educação Infantil de Belo Horizonte }\end{array}$ & $\begin{array}{c}\text { Eliana Batista } \\
\text { Souza }\end{array}$ & 2018 & Dissertação & UEMG \\
\hline
\end{tabular}

Fonte: Elaborado pelo autor

Quadro 2 - Artigos na temática de professores homens na educação infantil das reuniões da Associação Nacional de Pós-Graduação e Pesquisa em Educação - ANPED

\begin{tabular}{|l|l|l|l|}
\hline Ano & Grupo de trabalho (GT) & Autor & Titulo \\
\hline 2015 & $\begin{array}{l}\text { GT 07 - Educação de } \\
\text { crianças de } 0 \text { a } 6 \text { anos }\end{array}$ & José Edilmar de Souza & $\begin{array}{l}\text { Homem docência com crianças pequenas: o } \\
\text { olhar das crianças de um centro de educação } \\
\text { infantil }\end{array}$ \\
\hline 2013 & $\begin{array}{l}\text { GT 23 - Gênero, } \\
\text { sexualidade e Educação }\end{array}$ & $\begin{array}{c}\text { Mariana Kubilius Monteiro; } \\
\text { Helena Altmann }\end{array}$ & $\begin{array}{l}\text { Trajetórias na docência: professores homens } \\
\text { na educação infantil }\end{array}$ \\
\hline
\end{tabular}

Fonte: Elaborado pelo autor

Quadro 3 - Artigos na temática de professores homens na educação infantil em periódicos QualisA1 em educação

\begin{tabular}{|l|l|l|l|}
\hline Revista & Ano & Autor (es) & Titulo \\
\hline $\begin{array}{l}\text { Cadernos de } \\
\text { Pesquisa }\end{array}$ & 2014 & $\begin{array}{l}\text { Mariana Kubilius Monteiro; } \\
\text { Helena Altmann }\end{array}$ & $\begin{array}{l}\text { Homens na educação infantil: olhares de suspeita } \\
\text { e tentativas de segregação }\end{array}$ \\
\hline
\end{tabular}

Fonte: Elaborado pelo autor 